\title{
Challenges international married couples face during their first year of graduate studies
}

\author{
Wa-Mbaleka, Safary $\bowtie$ \\ Adventist International Institute of Advanced Studies, Philippines (wa-mbalekas@aiias.edu) \\ Peña de Vargas, Ana Mercedes \\ Adventist International Institute of Advanced Studies, Philippines (penaa@aiias.edu) \\ Varani Lisal, Melisa \\ Adventist International Institute of Advanced Studies, Philippines(lisalm@aiias.edu) \\ Paul, Sharon \\ Adventist International Institute of Advanced Studies, Philippines (paulns@aiias.edu) \\ Lipen, Zachary \\ Adventist International Institute of Advanced Studies, Philippines (lipenz@aiias.edu)
}

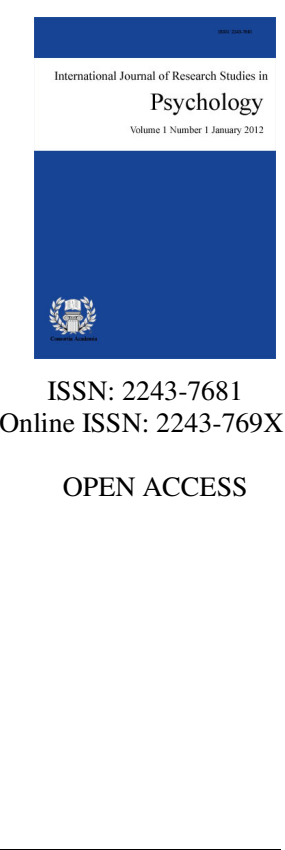

\section{Abstract}

In recent years, the international university under exploration, located in the Luzon region of the Philippines, has been attracting more and more international students from different countries all around the world. Not only single students, but also married students, are coming with their entire immediate families. These married couples have, however, to adapt to the new international environment with various challenges, particularly during their first academic year. Using qualitative methodology through interviews and observations, this case study reports real-life events of married couples with children, the challenges they faced during the first year of studying abroad and the impact on their families, wellbeing and academic performance at this university. This report also includes the coping strategies that these international students have used successfully to deal with their challenges.

Keywords: married couples; challenges; international students; well-being; academic performance; coping strategies; case study 


\section{Challenges international married couples face during their first year of graduate studies}

\section{Introduction}

In this interconnected era, many people all around the world are traveling to different countries, for different reasons. Many are moving with their immediate family members. Keeping a family happy has become a big challenge nowadays, and it becomes more perplexing when a family moves to a completely unknown place, to a different culture, where everything is new for all the members of the family. Although moving from one place to another is not a new phenomenon, it is more frequent in this globalized world where nothing seems too far and nothing seems too difficult to reach.

Many of the migrants travel with the purpose of studying. Hayes and Taylor (as cited in Zhou, Jindal-Snape, Topping \& Todman, 2008) estimated approximately more than a million students and scholars attending international institutions of higher education worldwide. A sizable number of them move for study purposes. There are some challenges that affect families who live abroad, specifically during the time of their studies, which is the focus in this research. Culture shock is part of these challenges; a phenomenon that happens as someone's adjustment process to a new place (Pedersen, 1995).

Berry, Kim, Minde, and Mok (as cited in Poyrazli \& Kavanaugh, 2006) suggested that students frequently experience more difficulties in adjusting than other immigrating groups. This fact is similar to the experience of married couples with children at the university explored in this study. Therefore, the purpose of the study was to explore and understand the challenges married couples with children face during their first year of graduate studies, the impact on their families, and their coping strategies that can be adopted by international married students in similar situations.

\section{Literature Review}

The topic of international married students and their challenges has been expounded in several studies (see for instance, Eustace 2007; Pascoe, 1998; \& Wa-Mbaleka, 2013). Some of these studies focused on the assessment of the problem, while others have dealt specifically with the challenges, such as cultural shock, language acquisition, and children issues. This review attempts to make a brief survey of these challenges.

\subsection{International Married Students}

International married students often face all the challenges of adjustments that their single peers face too, such as trying to meet new people with all that implies, missing traditional food, doing assignments and reports, and others. Moreover, the additional pressure of helping their family to cope with their transitional process is an added responsibility that comes with different challenges. In this sense, their situation is unique and deserves special attention. The adaptation of international students can be affected by their marital status. Single students may experience very stressful situations that can result in isolation and loneliness. On the other hand, however, being with a spouse or family can offer social support (Eustace, 2007) that single students may not access. This idea is corroborated by Wa-Mbaleka (2013). In his study on married single students, he found that only one out of eight students recommended that it is alright for prospective students to study abroad without their families with them. In that study, two participants in that study indicated that they would provide all the facts on married single life and let the prospective students make their own decision, but five of the participants indicated that they would not recommend married single life to prospective students. These findings revealed the significant importance of having family when studying as an international student.

Poyrazli and Kavanaugh (2006) affirmed that in the specific situation of international married students, the marital relationship may be working as a buffer. Since these students are married, they do not feel the need to 
explore other possible relationships. They meet their social support needs at home through their spouse or family. Pascoe (1998) observed, however, that depression, acute unhappiness, resentment, fear, loss of identity and privacy, longing for one's own wonderful support system back home, are possible symptoms of a spouse's culture shock. This information is particularly relevant because the emotional need of the spouse must be taken into account in any study on the complex situation of international married students.

\subsection{Culture Shock}

Married couples with children, who travel to another country to work or study, have to deal with cross-cultural shock, which is a crucial factor in the adjustment process. Pascoe (1998) indicated that the first reaction an individual has about an uncertain and different environment, is culture shock. Culture shock is an adjustment experience filled with the imbalance between one's own cultural background and the expectations of the new culture. The farther apart the two cultures are the stronger and/or the longer the culture shock experience.

With the purpose of explaining the adjustment process of international students, Gonzalez (2004) presents the U-curve hypothesis, which is divided into three phases: positive attitude, critical outlook about the host culture, and coping strategies development. The first phase (positive attitude) comes with few adjustment problems and can last from entry to up to six months; the second one (critical outlook of the host culture) can be filled with more adjustment problems. The third phase is coping strategies development, which can last from the second year until they go back to their countries. The length of period of these different phases varies in literature, simply because people experience culture shock differently.

This transition often includes extra stressors from the process of acculturation, particularly coming from diverse cultural backgrounds (Chai, Krägeloh, Shepherd, \& Billington, 2012). Some of the causes of cultural shock are lack of ability to communicate, changes in habit, changes in relationships, loss of cultural understanding, emotional confusion, and disorientation of cultural principles (Baumgartner, Dybdahl, Gustin, Kuhn, Merklin, \& Moyer, 2009). Coping with culture shock is often a painful process, and is accompanied by stress (Lingenfelter \& Mayers, 2003).

All international students go through culture shock, which, however, is manifested differently with different individuals. In order to cope with this challenge, some students seek help from friends, relatives, faculty members, or their own communities (Wa-Mbaleka \& Ryszewski, 2012). Furthermore, according to Wa-Mbaleka and Gaikwad (2013), in the case of the Philippines, discrimination is sometimes a common practice in international institutions of education. Therefore, another potential challenge for international students is the issue of discrimination, whether real or simply perceived.

\subsection{Second Language Learning}

In addition to culture shock, second language learning tends to be one of the major hindrances to academic and professional success. English language proficiency is something that international students cannot achieve overnight. It takes years of learning to master a new language (Saville-Stroike, 2012; Wa-Mbaleka \& Gaikwad, 2013). Immigrant status and language barriers have given explanation on cultural/ethnic disparities (Avila \& Bramlett, 2013). Additionally, it has been found that trainers cannot assume that all participants in training courses understand the technical terminology used (Welsh, 2012). Furthermore, international students often explain difficulty with English language expertise and communication as the main difficulty affecting their wellbeing (Watkins, Razze, \& Richters, 2012). Thus, language barriers are possibly some of the most common problems for international students from diverse linguistic backgrounds.

Fortunately, this transition process is a temporary problem for most students. Eventually, due to the many opportunities to practice the second language in a context of immersion, many students are eventually able to understand and make themselves understood in the new language. One of the approaches that have been 
successfully used to help students learn a new language is the content and language integrated learning that consists of teaching a subject matter in a second language as a way to fulfil a double purpose. For example, students of English may learn it through taking a history subject taught in English (Lightbown \& Spada, 2013). They learn English while taking history, instead of having to learn English first before taking the other subjects taught in English. The good news is that, no matter how hard a language may seem, learning a new language is not an impossible task for international students (Wa-Mbaleka \& Gaikwad, 2013).

\subsection{Children Issues}

Some of the students who travel with their families have children. The fact that these children are leaving their friends, school, and known world, affects their behavior, attitude, and experience abroad. Children experience culture shock too and many of them can lose part of their national identity; some of them may experience isolation, which may affect their future life (Rabe, 2009). Since the children go along with the decision parents make, they often feel angry and frustrated about it. The best concept to label children in this situation is third culture kids (TCKs), first used by Ruth Useem, back in the 1960s. Becoming angry, impatient and rejecting the new culture, are just some of the reactions that TCKs may show while trying to adapt to a new location and this may lead them to social isolation (Pollock \& Reken, 1999). Pollock and Reken (1999) came up with the concept cross-cultural kid to refer to all the children who had grown up connected to two or more cultural worlds during childhood. This TCK or cross-cultural kid phenomenon is on the rise due to the increased migration caused by globalization.

Children are exposed to many different cultures and different languages. Such an exposure has an advantage to their adult life. Because children are more flexible than adults, children take in foreign cultures as part of their own culture, a culture between cultures. On the contrary, adults living in a foreign country observe rather than take in foreign cultures (Pollock \& Reken, 1999). The observer of the culture cannot internalize the new culture as does someone who integrally immerses himself or herself in it. The fact that the outcomes of the adjustment international students are, to some level, contingent upon relationships established with familial students, can make the adjustment process more complex (Hammer, 1992; Olaniran, 1993). This is why marriage can play an important role in the lives of international students. Married students may experience the adjustment progression in a different way than single students do. It is important to understand the role culture plays in the adjustment process, as well as the ways culture relate to adjustment. Poyrazli and Kavanaugh (2006) recommended further studies to understand the diversity of international students. The insight gained from the current study is meant to better assist international students in their adjustment process.

\section{Theoretical Framework}

Challenges encountered by both married and single international students have been a difficult social, and ethical problem in various contexts (Eustace, 2007; Gonzalez, 2004; Wa-Mbaleka, 2013). This reality of life is no exception to international married student with children during their first year. Their experience is linked to a number of theories that have been established over the years. This study is primarily based on a social identity theory presented by Worchel (1998), who stated that social identities play a significant role in the individual's self-concept. The social identities mentioned by Worchel include nationality, religion, profession, gender, race, or political preferences. Cross-cultural process may cause people to consider themselves like "little fish in bigger ponds". Eventually, this difficult situation might make them anxious and lead them to change their perceptions of self and identity (Zhou, Jindal-Snape, Topping \& Todman, 2008).

Cultural syndromes are another source of intercultural interaction difficulties. The three major cultural syndromes are tightness and looseness culture, individualism-collectivism, and cultural complexity. When people apply sanctions for minor deviations from rule, it is called tightness culture; while looseness culture is the opposite, when deviation is tolerated. In collectivist cultures people depend on each other, family, tribe, and other social support networks. In individualistic societies, relationships are not as important as they are in 
collectivist societies (Triandis, 2001).

Studying at the tertiary level and living in another country are challenging experiences. International students from different cultural backgrounds experience a wide range of transition issues. This discussion has demonstrated that international students, both married and single, face several challenges during their academic journey. According to Wa-Mbaleka (2013), most of available studies were conducted in Australia, Europe, and North America. Rarely are studies conducted in Southeast Asia, where this study took place. The purpose of the study focused on the challenges married students with children face during their first year of study at a private Christian university and how they cope with those challenges.

\subsection{Research Questions}

$>\quad$ What are the challenges married couples with children face during their first year at an international tertiary institution?

$>$ How do these challenges affect their families, wellbeing and academic performance?

$>\quad$ What are some practical coping strategies of families with children for overcoming these challenges?

$>\quad$ What lessons can be learned for prospective international married students with children?

\section{Methodology}

The purpose of this case study was to explore, identify and understand the challenges married couples with children faced during their first year of study at the selected institution, as well as the strategies used to cope with those challenges. Since this is a social reality and part of the everyday activities of the participants, interpretivism was a suitable philosophical underpinning, as it explains phenomena through uncovering the intentions of the actors involved (Wagenaar, 2011). Qualitative research was utilized in conducting this case study. The case study design allows researchers to maintain the integrated and significant characteristics of real-life events (Yin, 2009), for example the challenges international married students face. It helped to explain what was occurring among married couples with children at the selected institution.

\subsection{Research Design}

This research utilized the case study design because it is focused on examining an existing phenomenon exhaustively and within its everyday perspective, particularly when the boundaries between the phenomenon and perspective are not openly evident (Yin, 2009). Qualitative research was utilized in conducting this one-case study. The case study design allows researchers to maintain the integrated and meaningful characteristics of real-life events (Yin, 2009), such as the challenges international married students face. It helped to explain what was occuring among the married couples with children at this international university.

\subsection{Research Setting}

The data for this study was collected at an international university located in the Luzon province of the Philippines. The university is a Christian tertiary level educational institution that traces its formal beginning back to 1957. The academic programs include theology, business, public health and education. The university offers both masters and doctoral programs. The majority of the students are foreigners and many of them are married couples with children.

\subsection{Research Participants}

Purposive sampling was utilized to identify the four couples who participated in this study. Four married couples with children from four continents were involved in this study. These families were from Mexico, 
Rwanda, Georgia, and Indonesia. All the participants were completing their graduate studies at that same university. The participants are identified by an assigned code instead of their actual names.

\subsection{Population and Sampling Procedure}

The research population of this study included all international married couples with children at the selected university. The participants were selected among those who had been studying there for more than one year, in order to meet the specified goal of identifying the challenges and coping strategies during the first academic year. A purposive sampling strategy was used, since this study intended to obtain data from those who can provide specific in-depth information (Creswell, 2012). The method of drawing the purposive sampling correctly was based on the following characteristics: to have at least one child, to live inside the university campus, to have spent more than one year of study at this university, to make sure both husband and wife as active students at the time of the data collection. Other characteristics were: couples having at least five years of marriage and couples willing to share their experience openly. These criteria were set in order to obtain a more accurate and attainable purposive sampling of the target population.

\subsection{Data Collection and Instrumentation}

The recruitment of the participants was done through face-to-face invitation, in which the date and the place of the interview were discussed. The participants signed an Informed Consent Form before the interviews. Both husband and wife were included in the interviews. The data was recorded with different electronic devices and then transcribed. The study required us to observe and document all needed data (Creswell, 2012). For this specific case study, oral interviews and observations (Yin, 2009) were used to collect data. Semi-structured one-on-one interviews were conducted to collect the data. Each interview session lasted about a half an hour to maintain the interest of the participants. The instrument was reviewed and validated by three experts in the research area, a practice used commonly in qualitative research (Creswell, 2012). A pilot case was conducted to improve the data collection plan and the actions to be followed, as proposed by Yin (2009). Only one family was included in this pilot case. It helped in trying and adjusting the interview guide. The collected records were triangulated on different sources, such as interviews and observation, to corroborate evidence and develop an accurate and credible report (Creswell, 2012). After the triangulation process, the collected information was verified by the participants, through member checking. The next step was to ensure the information through the member checking process, which is the procedure to verify with the participants the accuracy of the report (Creswell, 2012).

\subsection{Researcher's Positioning}

As required in most qualitative research designs, it is important to state here the researcher's positioning or researcher's reflectivity. The majority of the researchers in this study were also international married students. While identifying with what the research participants must have helped enrich the understanding of the findings of this study, this fact may have caused us to miss some important information. One of the researchers, however, is a professor and does not fit the selection criteria. He provided additional input that could have been missed.

\subsection{Data Analysis}

The data analysis for this study relied on theoretical propositions, based on the research questions. These propositions shaped the data collection plan and consequently the analysis was straightforward (Yin, 2009). Propositions helped to determine which data was relevant for the study (see Table 1). These propositions are: (a) "International students experience many challenges upon their arrival in a new country" (McAllister, 2007, p. 30); (b) Marriage can be either supportive or stressful for international students (Eustace, 2007); and (c) Family support, truthful relationships, and exercise are coping strategies to overcome the challenges faced by international students (Hui, 2007). 
In order to organize and summarize the information for the analysis, the data went through a level of abstraction that went from codes, categories, and themes (Creswell, 2012). Linking the data to propositions was the technique used for analysis. Computerized software (Microsoft Word and Excel) was utilized to encode and classify large quantity of narrative wording. The main ideas were identified to facilitate the accurate interpretation.

\section{Results}

The results of this case study are based on four themes that were previously established. These themes are the challenges that international married couples with children face during their first year at the selected international university, the impact in their lives and families, the coping strategies that they used to overcome these challenges and the recommendations they shared for prospective married students with children. Table 1 synthesizes the four themes and the related categories and codes.

\section{Table 1}

Summarized Data

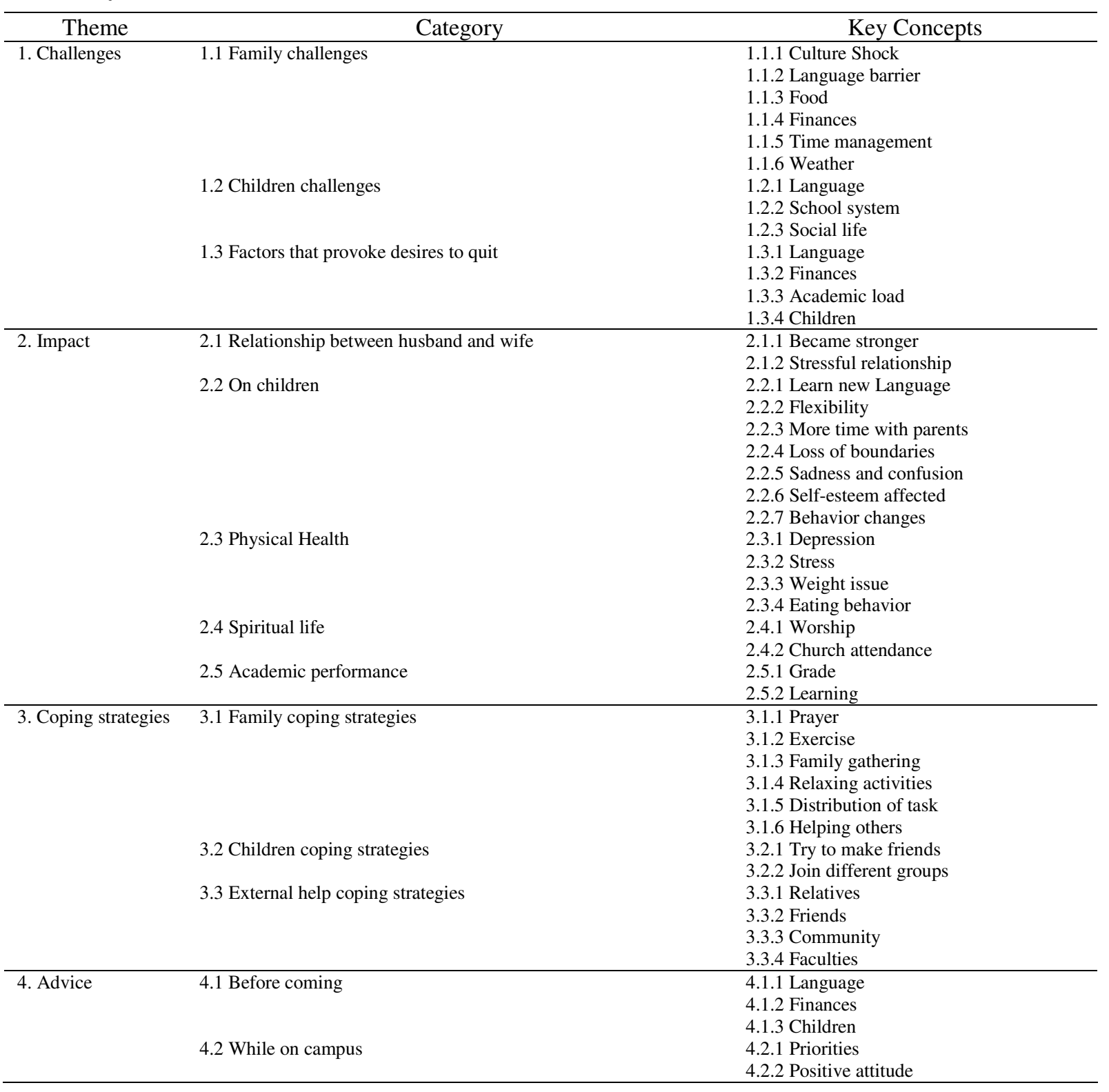




\subsection{Theme 1: Challenges}

Studying at the tertiary level in an international environment with the entire family has a wide range of transition challenges. The first theme in this study was the identification of the challenges international married couple with children face during their first year studying at the selected university. The challenges are classified into family challenges, children challenges, and factors that provoke desires to quit.

Results of this research showed that one of the major challenges of the participants was the culture shock. For international students, the process of transition often includes additional stressors from the process of adaptation. The fact that people with whom students relate come from so many different cultural backgrounds makes the process even more challenging. "To live with people around you with whom you have so little in common makes one feel more stressed" (Family 3).

In addition to culture shock, second language acquisition tends to be one of the major challenges to academic and professional success. Since most of the interviewed couples speak a mother tongue other than English, they mentioned how language barrier was a main difficulty they had to face upon their arrival at the university. One participant from Family 1 said, "English is very challenging for me. When I came here you know, I was struggling, I was hospitalized in the English Center (Laughter). So, I was missing my country, because of it."

It is not surprising that food became another challenge for these foreign families, as literature has already revealed the same (Decapua \& Wintergerst, 2004; Wa-Mbaleka, 2013). Some of the participants mentioned for example the lack of some of the ingredients they used in their home countries. Additionally, most of the family had difficulties with managing their time. "I mean time management is challenging. We are coming to study and yet we need to cook, we need to clean the house, we need to take care of the children, many things like that" (Family 3).

Most of the couples indicated that finance was also a challenge for their families. One couple assured they tried to make some provision for the whole program, but unfortunately, new challenges affected their budget. Some of the couples found that the weather was one challenge at the beginning of their living on the university campus, for some it was too hot, while others found the humidity quite disturbing.

Children also had their own issues when they started life in this international setting. All of the children of the participants indicated to them that language barrier was their main challenge when they arrived at this university. Referring to their son, a couple said, "The first problem was the language. He could not relate to his peers, so he felt ignored, neglected; it was a problem. During the first days, he often cried, he missed our country" (Family 1).

Furthermore, the school system was another challenge. Most of the parents mentioned that the school system for the children at this institution is different from the system in their respective countries, such as the schedule, discipline and the curriculum. "Here they are at school until 4:30 so it was like all day long and for us is too much and hard for us to understand" (Family 2). Regarding the curriculum, one family added that the gap between the way teachers teach here and the way students are learning is huge compared to their own country.

Most of the families found that language barriers, financial issues and academic load pressure were factors that began in them the desire to quit. Family 1 stated, "And you feel at a certain moment that the load of studies is higher or your expectations are higher than you think you can manage, that is the reason of thinking that maybe I should drop, I will not be able to make it." Another important thing that caused them to consider the possibility of quitting was their concern for the children. Parents felt bad when they perceived the difficulties their children had to face in their adjustment process. 


\subsection{Theme 2: Impact on Families, Wellbeing, and Academic Performance}

Several of the challenges mentioned above have affected the life of these married couples with children, particularly during the first year of their study. The second theme is the attempt to understand how these challenges affect their families, wellbeing and academic performance. There are five categories in this theme including marital relations, impact on children, physical health, spiritual life and academic performance.

One of the main aspects of the lives of the participants affected by the new cross-cultural experience was the marital relation. Most of the participants admitted there was a lot of tension during the first stressful days of adjustment. They added, however, that eventually the bond between them became stronger and the relationship more mature.

The impact of moving to Philippines upon the children of the participants had both a positive and a negative effect. For the positive impact, the families shared that their children learned a new language, they were more flexible with other people because of the exposure to so many different cultures, and they had more quality time with parents than they used to have back in their countries where parents were working the whole day. "There is something which is ... more rewarding when we are here as a family, we have more time to be together" (Family 3).

In contrast, the same families said that the children experience loss of boundaries. Some of them start to feel too independent, they go to school by themselves, sometimes they have to cook their own food, and spend many hours during the day without the parents. In addition, children experience sadness and confusion because of the changes they face when they move to another country and leave their relatives and friends.

Self-esteem and behavior are also negatively affected in children because of the pressure in the new environment, the new school, the language barrier and poor social life at the beginning. In Family 1, one stated, "Another challenge was that the self-esteem was low in their first year. Especially the youngest! His self-esteem... we couldn't even recognize him, his behavior, he was totally different, his personality was dramatically changed here."

Three of the four families indicated that stress has affected their health. Some of them even have suffered from depression. The families also shared that they do not get enough sleep. One of the participants in Family 1 said, "I feel that I am chronically sleepy (Laughter)". Three of the couples have gained weight because of the irregular eating schedule and lack of exercise, while the wife of Family 2 said she lost 12 kilos during the first year at this international university. She lost her appetite because of depression.

There is one sensitive aspect for the interviewed families. All participants said that even though they tried to do daily worship with the entire family, it was very difficult to achieve. Therefore, worship had become like a routine - quick and short. Family 4 stated that, "Sometime worship becomes a routine for the sake of the son.... for the sake of the children but not really for the spiritual life". Husband and wife have classes in the morning, afternoon; and at night they complete their assignments. There is not enough time to do worship properly.

On the other hand, two of the four couples said that their relationship with God has increased due to the challenges they have faced. Three of the families said they are involved in church activities and stated that being involved has helped them to keep their spiritual life alive.

All participants said that their academic performance was affected by the challenges that they faced. Some of them obtained low grades. Some of the reasons were the language barrier, the heavy load of assignments, lack of sleep, lack of concentration, stress and others. Others had good grades but they admitted the learning process was affected. The husband in Family 4 stated, "Honestly, the kind of educational system load and expectation is totally different back home. ... Where I studied before, crucial skills such as quality academic writing and critical thinking were not taught, so I was struggling from the very beginning..." This comment was almost 
recurrent among the participants.

\subsection{Theme 3: Coping Strategies}

Despite the several challenges, most of the participants were able to cope with them during their first year. The coping strategies employed by the participant belong to three types: family coping strategies, children coping strategies, and external help coping strategies.

Most of the couples dealt with their challenges through prayer as someone in Family 1 stated, "My personal answer to cope with all the challenges is to pray. We should never underestimate the power of prayer to face real and daily life situations. The word 'prayer' should never be used along with the word 'just' lest we convey a wrong message about the meaning and the importance of prayer".

Another strategy that the participants used to counteract stress was regular physical exercises. In addition to this, relaxing activities such as massage and watching funny videos and movies together were also mentioned as part of a set of coping strategies.

For others, church activities provided a way out to break the stressful routine of the week. Altruistic and religious service was also used as effective coping strategies. At some point, a couple said that by distributing the household chores between family members, the load became lighter and the stress was significantly reduced. Besides, several couples had regular family outings in an attempt to experience the recreational habits that the family had while they were still in their home country.

In a short period of time, all the children were able to cope with their challenges through making friends from school, being friendly and sharing things with their friends in a short period. One family stated that being outgoing is one of the characteristics that help their children to cope with stress. Most of the interviewed couples pointed out that having a positive attitude helps reduce the length of the adjustment process. Children were also able to cope better with the new cross-cultural experience through the participation in church and other extracurricular activities such as adventurers' and pathfinders' club programs, the learning of musical instruments and other religious programs.

The majority of couples indicated that another crucial factor was the support received from friends, fellow students, and faculties from their countries, or coming from similar culture. The amount of physical, mental and emotional help received through this means cannot be underestimated. The wife from Family 2 mentioned an instance when the empathy from a neighbor was crucial to her. One day shortly after her arrival, she was crying so loud that her voice could be overheard. Her neighbor came to comfort and encourage her.

\subsection{Theme 4: Advice}

This segment briefly recaps the recommendations that the participants felt are important for prospective students, especially those families who may want to pursue further education at this or similar institutions elsewhere. In reference to challenges faced by studying couples with children, a participant remarked, "Do not underestimate changes." The unexpected does happen, thus families who are planning to complete their studies at an international university must expect the unexpected.

The participants felt that married couples with children, who wish to further their studies particularly at this university, seriously need to get themselves familiarized with what is expected and the unsuspected challenges before they move. By doing so, families would be more mentally prepared to face the challenges with a more positive and realistic attitude.

The majority of the families interviewed highlighted the same sentiments that families who are planning to attend this university must do their best to learn or improve their English as much as possible before they come. Family 1 in particular emphasized to learn and practice English before attending this university. This might 
reduce or even help avoid the frustration that comes with unanticipated extended time in the English language center. This has frustrated sponsors and unsuspected families who anticipated a shorter length of time for study.

Most of the interviewees consider that it is important to have enough savings before coming attending this university, even in the case of families who are on full sponsorship. One participant indicated that, "Financial issues are many ... to have enough savings before coming here is advisable." Necessary financial provision before arrival at this or any other international graduate institution is highly advised.

All of the families interviewed advised that it is not an ideal plan to have children born while studying or to come with infants. It is difficult to attend to the needs of babies and concentrate on studies at the same time. This is particularly true if both husband and wife plan to study. On the other hand, families who are coming with school age children need wisdom to make them aware of the expected challenges (language, different educational system, culture shock, etc..) prior to their coming.

Once on campus, the interviewees see that the focus of advice shifts from how they can prepare to how they can handle or adjust. Therefore, prioritizing and having a positive attitude toward looming challenges is discussed hereafter.

Half of those interviewed stated that there are many things, especially life challenges, that can easily distract study and work performance. Therefore, prioritizing study, spiritual life, family, and recreation with other demands is of prime significance for success. Someone in Family 1 said, "Leave everything and go for a walk or go sometime to enjoy as a family at the beach. Take the whole family out."

The majority of the participants acknowledged that the challenges are always there for every family, but coming to a new environment with children poses greater risks. Simultaneously, demands imposed by respective courses add more burdens. Therefore, it is advisable to maintain a positive attitude. One must know that he or she can get through because others have successfully traveled this road before.

Prayer and faith in God reinforce an optimistic approach to all challenges. In the opinion of most of those interviewed, prayer was found to be helpful to overcome the challenges found as cross-cultural students at this university. This is no surprise, given that this is a Christian institution and most students there were Christian.

\section{Discussion}

The findings of this study provide lessons from challenges, impact, and coping strategies experienced by international married couples with children at the selected university. In this section, the analyzed data is summarized to address the research questions.

In terms of challenges, Pascoe (1998) indicated that the first reaction an individual has about an uncertain and different environment is called culture shock. Precisely, this was the first and most mentioned challenge our participants identified. Our findings confirm that coping with culture shock is often a painful process, and is accompanied by stress, as stated by Lingenfelter and Mayers (2003). The good news is that sooner or later, most people survive culture shock.

On the other hand, the couples stated that their spouses were a great help in times of pressure while studying. That declaration is in line with Eustace's (2007) finding; he stated that being with a spouse or family can offer social support. At the same time, Pascoe (1998) observed that depression, acute unhappiness, resentment, fear, loss of identity and privacy, longing for one's own wonderful support system back home, are hallmark emotions of culture shock. Some of our female participants suffered from depression during their first year at this university.

Becoming angry and impatient, and rejecting the new culture are some of the reactions that TCKs may have while trying to adapt to a new location and this may lead them to social isolation (Pollack \& Reken, 2001). That is the same picture our participants depicted about their children. Children must therefore be taken into 
consideration when planning to study in a foreign country.

Language barrier was pointed out as one of the major challenges that our participants faced during their first year at this university. Just as indicated by Wa-Mbaleka and Gaikwad (2013), it takes years of learning to master a new language. Some of the participants spent more than six months at the university's English Center before they could begin their actual graduate or doctoral program.

\section{Conclusion}

Culture shock and language barrier are possibly the most challenging problems for international students from various linguistic backgrounds. This situation was also experienced not only by the parents but also by the children, particularly during their first year at this international university. The research participants had to adjust to the local food, weather, financial limitations, and time management issues. For the children, the school system created a challenging life at the beginning. In many cases, they had to adapt to a new system that was different from the one they were used to in their home countries.

Notwithstanding the challenges, the impact of the stressful transitional process upon the relationship between spouses was not too negative. Although there were moments of impatience due to the busy schedule, in the long run, the participants indicated their relationships became stronger. The same could not be said of the wellbeing. Other aspects of life are affected when, due to the academic pressure, the students experience irregularity in their eating schedule, sleeplessness, and weight gain or loss. These challenges have an impact not only upon the couples but also in the life of their children, both positively and negatively.

The impact on spiritual life goes up and down but most of the families reported that they became closer to God in times of difficulties. These challenges have a more adverse effect on people at the beginning but, eventually, they learn to deal with them through the aforementioned coping strategies.

Many of the participants cope with their challenges through prayer. One of the practical ways of coping is family gathering even though there are many other challenges such as academic requirement, financial and children problems that take place in the family. Other employed strategies that participants reported were regular exercise, being involved in church and community activities, recreational and relaxing activities.

Finally, it is noteworthy that although the four families that participated in this study came from four different countries, they gave very similar answers and came close to the same conclusions. Worthy of notice is also the fact that the family that seemed to have a more positive attitude was the only family that had a better command of the English language prior to their coming to this university.

\subsection{Recommendations}

Since this was not a quantitative study and, therefore, did not aim at extrapolating its results, the researchers believe, nevertheless, that the findings could be useful in two specific ways. First, we could identify the need for further studies on the subject. Second, there are some recommendations that could benefit future students who might consider attending the same university under the same circumstances of the participants. Other graduate international institutions could also take advantage of this study to evaluate whether it might reveal similar findings in their setting.

The administration of the university under exploration could conduct other studies in order to gain understanding that can help them to better prepare their future international students. They can use the findings in this study to understand better the needs and challenges of their international married students, and develop programs to help them better. In the meantime, the following suggestions could be given to both potential students as well as to those newcomers of the institution.

Prospective students are strongly encouraged to work as much as possible to improve their English language 
skills before they attend this international university since English is the sole medium of instruction there. The language learning process and the academic pressure of a graduate institution are already stressful enough. If financial challenges are added, stress could go beyond a manageable level. For that reason, it is recommended that even sponsored students make all the necessary financial provisions to deal with potential financial limitations.

One of the main sources of stress for participants was that of the challenges that their children faced during the transition period. Parents not only needed to cope with their own stress, but also suffered seeing their children going through the challenges of second language learning, culture shock and general disorientation. Therefore, we recommend that the university provide or suggest to prospective students with children some guidance, materials, and ideas similar to those used to help TCKs. If the children (regardless of their age) receive some orientation, the adjustment process once at the university may be shorter and less traumatic.

Even though findings have mostly confirmed the literature, this study has some limitations. The time constraint was one of the limitations. Only two months were allocated to complete the study. Besides, the fact that neither the interviewers nor the participants speak English as their mother tongue implied some limitations in the communication process. We did not interview the children, and that could have been an important source of data for the betterment of this type of study. Further, the lack of familiarity between participants and interviewers might have prevented sincere and complete answers from the participants.

In order to have a deeper knowledge of the complex experience of the married students with children, we suggest that new studies be carried out, focusing specifically on the perceptions of the wives of the students and of their children. We also see the need of new studies involving a larger number of participants and using a mixed approach; this would shed more light on the understanding of what these people go through. The results of these studies could increase the academic knowledge on the subject. More than that, it could help countless international students to cope with their ill-understood experience.

\section{References}

Avila, R. M., \& Bramlett, M. D. (2013). Language and immigrant status effects on disparities in Hispanic children's health status and access to health care. Maternal and Child Health Journal, 17(3), 15-23. http://dx.doi.org/10.1007/s10995-012-0988-9

Baumgartner, E., Dybdahl, J., Gustin, P., Kuhn, W., Merklin, L., \& Moyer, B., (2009) Passport to mission $\left(3^{\text {rd }}\right.$ ed.). Berrien Springs, MI.: Institute of world mission.

Chai, P. P. M., Krägeloh, C. U., Shepherd, D., \& Billington, R. (2012). Stress and quality of life in international and domestic university students: Cultural differences in the use of religious coping. Mental Health, Religion \& Culture, 15(3), 265-277. http://dx.doi.org/10.1080/13674676.2011.571665

Creswell, J.W. (2012). Educational research: Planning, conducting, and evaluating quantitative and qualitative research $\left(4^{\text {th }}\right.$ ed.). Boston, MA: Pearson Education.

DeCapua, A., \& Wintergerst, A. (2004). Crossing cultures in the language classroom. Ann Arbor, MI: Michigan University.

Eustace, R. (2007). Factors influencing acculturative stress among international students in the United States (Doctoral dissertation). Available from ProQuest Dissertations and Theses database. (UMI No. 3291368)

Gonzalez, V. (2004). Second language learning: Cultural adaptation processes in international graduate students in U.S. Universities. Lanham, MD: University Press of America.

Lightbown, P. M., \& Spada, N. (2013). How languages are learned ( $4^{\text {th }}$ Ed). Oxford, UK: Oxford University.

Lingenfelter, S. G., \& Mayers, M. K. (2003). Ministering cross-culturally: An incarnation model for personal relationships ( $2^{\text {nd }}$ ed.). Grand Rapids, MI: Baker Academic.

McAllister, W. (2007). Health networks of foreign students (Master thesis). Available from ProQuest Dissertations and Theses database. (UMI No. 1449809) 
Wa-Mbaleka, S., Peña de Vargas, A, M., Varani Lisal, M., Paul, S., \& Lipen, Z.

Pascoe, R. (1998). Culture shock!: A wife's guide. Singapore, Singapore: Times Books International.

Pedersen, P. (1995). The five stages of culture shock: Critical incidents around the world. Westport, CT: Greenwood Publishing.

Pollock, D. C., \& Van Reken, R. E. (1999). Third culture kids: Growing up among worlds (Rev. ed.). Boston, MA: Intercultural.

Poyrazli, S. \& Kavanaugh, P. (2006). Marital status, ethnicity, academic achievement, and adjustment strains: The case of graduate international students. College student journal, 40(4), 767-780.

Rabe, M. (2009). Culture shock!: Living and working abroad. Eugene, OR: Wipf and Stock.

Hui, Y. Y. R. (2007). International students preferences for coping strategies, counseling approaches and counselor characteristics (Master thesis). Available from ProQuest Dissertations and Theses database. (UMI No. 1445990)

Saville-Stroike, M. (2012). Introducing second language acquisition (2 ${ }^{\text {nd }}$ ed.). New York, NY: Cambridge University. http://dx.doi.org/10.1017/CBO9780511888830

Triandis, H. (2001). Individualism-collectivism and personality. Journal of Personality, 69, 907-925. http://dx.doi.org/10.1111/1467-6494.696169

Wa-Mbaleka, S., \& Ryszewski, S. (2012). Coping with culture shock in second language settings: A phenomenological study in the Philippines. IAMURE International Journal of Education, 4, 14-33. http://dx.doi.org/10.7718/iamure.ije.v4i1.447

Wa-Mbaleka, S., \& Gaikwad, S. (2013). Current climate in higher education: Perceptions of international students in the Philippines. IAMURE International Journal of Education, 6, 1-13. http://dx.doi.org/10.7718/iamure.ije.v6i1.490

Wa-Mbaleka, S. (2013). Lived experiences of international male married singles students. International Forum, 16(2), 67-78.

Wa-Mbaleka, S. (2014). Publish or perish: Fear no more. Quezon City, Philippines: Central Book Supply.

Wagenaar, H. (2011). Meaning in action: Interpretation and dialogue in policy analysis. Armonk, NY: M.E. Sharpe.

Watkins, P., Razze, H. \& Richters, J. (2012). I'm telling you ... the language barrier is the most, the biggest challenge: Barriers to education among Karen refugee women in Australia. Australian Journal of Education, 56(2), 126-141. http://dx.doi.org/10.1177/000494411205600203

Welsh, J. (2012). Overcoming language barriers when teaching interprofessional groups. Emergency Nurse : The Journal of the RCN Accident and Emergency Nursing Association, 20(6), 3-6. http://dx.doi.org/10.7748/en2012.10.20.6.33.c9345

Worchel, S. (1998). Social identity: International perspectives. London, UK: SAGE. http://dx.doi.org/10.4135/9781446279205

Yin, R. (2009). Case study research: design and methods (4 ${ }^{\text {th }}$ ed.). Thousand Oaks, CA: SAGE.

Zhou,Y., Jindal-Snape, D., Topping, K., \& Todman, J. (2008). Theoretical models of culture shock and adaptation in international students in higher education. Studies in Higher Education, 33(1), 63-75. http://dx.doi.org/10.1080/03075070701794833 